static and explosive carbon and oxygen burning; explosive silicon burning; and the rapid, slow, and equilibrium capture of neutrons) which should occur in the various layers of normal stars. By a judicious mixing of the products of the various processes (coresponding roughly to the masses in each of the layers), they have succeeded in reproducing the observed abundances in the Solar System over a wide range of atomic numbers while using a rather small number of adjustable parameters.

On a still larger scale, W. D. Arnett (University of Illinois) and R. Talbot (Rice University) and B. Tinsley (University of Texas, Dallas) have formulated models of the evolution of our Galaxy as a whole which can reproduce the variations of total metal abundance with time and position in the galaxy as well as the percentages of matter now present in the form of gas and of stars of various masses and compositions. The models are by no means unique.

\section{Lizards and dune buggies}

from our Animal Ecology Correspondent

NoBody can doubt that increased leisure time available to people living in affluent societies is on the verge of creating immense environmental hazards. As it seems likely that time and money are going to be increasingly plentiful in the future, it is high time that ecologists and politicians got together to formulate useful legislation. This must be tailored to suit the specific ecosystems under pressure and no area, however barren, should be thought to be unworthy of inclusion.

The vast Mojave desert of the southwestern United States is one such barren area that has been used for more than a century for mining and domestic stock grazing. Today it is an important playground for the people of California and, as might be expected, the huge pressure so induced is taking its toll. At a conservative estimate there are 1.2 million motor cycles and 500,000 dune buggies in California most of which are used for scrambling and other off-road pursuits. A most useful pilot study of the impact of both vehicles and sheep on the Mojave has been made by Busack and Bury, and it is to be hoped it does not escape the attention of environmental decision makers (Biol. Conserv., 6, 179-183; 1974).

Dove Springs canyon, $23 \mathrm{~km} \mathrm{~N}$ and $9.5 \mathrm{~km} \mathrm{~W}$ of California City, was chosen as a study site since it is a popular place for buggy racers to display their talents. Three 1 ha plots representing heavy use, moderate use and no use were established and all the resident lizards in each were collected during a 3-day period. The conditions under which the census was made satisfy the restrictions as to effectiveness laid down by Zippin (Biometrics, 12, 163-189; 1956). Some lizards were caught by hand (the rare ones which were subsequently released), some were shot with 0.22 dust shot and others were shot with elastic bands. In the heavily used area, where the vegetation was severely reduced, only two lizards (Uta stansburniana) were caught. In the moderately used area 15 lizards were taken adding Callisaurus draconoides and Cnemidophorus tigris to the list. The biomass of lizards in this area was more than 48 times greater than that in the first area. The unused plot yielded 24 lizards (the three species mentioned plus Crotaphytus wislizenii) and had a biomass almost double that of the moderately used area. If lizards can be taken as indicator species of general ecological complexity-and being insectivorous this seems not unreasonable -there seems to be a case for speedy legislation to restrict dune buggy racing only to certain areas.

Grazing has different effects on lizards. Previous studies of desert vegetation have indicated that grazing does not greatly affect the diversity of plant species (Blydenstein, Hungerford, Day and Humphrey, Ecology, 38, 522-526; 1957; Gardner, Ecology, 31, 44-50; 1950). Protection from grazing serves to increase biomass without seriously affecting ecological complexity. In Gardner's study 30 years' protection from grazing brought about a $110 \%$ increase in biomass. The ungrazed study plot used by Busack and Bury yielded 36 lizards with a total biomass of $690 \mathrm{~g}$ ha $^{-1}$; of this $6 C$. draconoides comprised less than $10 \%$ of the total biomass. The plot which had been heavily grazed by sheep in the previous year revealed 17 lizards with a biomass of $185 \mathrm{~g} \mathrm{ha}^{-1}$. Interestingly, of this 17,11 were $C$. draconoides which comprised almost $70 \%$ of the total biomass. Phrynosoma platyrhinos and $C$. wislizenii were absent from the grazed plot. The likely interpretation of these observations is that the vegetational changes associated with grazing reduces to below an acceptable exploitable level the population of insects required by these species. $C$. draconoides is an agile lizard that favours open areas with scant plant growth and small rocks. The effect of grazing is to produce these conditions.

Both motor cycling and buggy racing have an important influence on community structure which could result in irreparable ecological damage. Strict control over who does what where in the Mojave will be required if the whole place is not to become unfit for lizards and thus, in the long term if not in the short, unfit for any kind of human use.

\section{Lattice defects in Freiberg}

from John Walker

THE latest in the series of international conferences on lattice defects in semiconductors, held at Freiberg from July 22-25, was opened by G. D. Watkins (General Electric, Schenectady) with his traditional review of spin resonance studies in silicon. The self-interstitial has still not been isolated, but seems to be produced in a positive-charge state during irradiation. It is then trapped by and changes place with the negatively-charged acceptors in p-type material. This trapping does not occur in n-type material, so the damage rate is lower, though boron counterdoping increases it. The importance of oxygen in radiation damage was emphasised by the identification of the Si-G3 and $\mathrm{Si}-\mathrm{G} 4$ centres as vacancies perturbed by oxygen atoms. Both defects anneal to give the well-known A-centre (an oxygenvacancy pair).

R. P. Messmer (General Electric, Schenectady), in his review of the theory of point defects in semiconductors, described the $\mathrm{X} \alpha$ scattered wave theory which has been used to illuminate the controversy between many-electron and one-electron treatments of the diamond vacancy. Apparently the electrons are not sharply localised at the defeci, but spill out into the surrounding lattice. Hence electron-electron interaction is reduced and the one-electron calculations are adequate. This is consistent with experimental results on silicon, but the data are not available for diamond.

In the diamond session, L. A. Vermeulin and colleagues (Universities of Reading and the Witwatersrand) reported the observation of sharp photoconductivity peaks in irradiated diamond crystals. which suggests the existence of bound states within the conduction or valence bands, J. W. Van der Sande (University of the Witwatersrand) has used the low temperature thermal conductivity of irradiated diamond to demonstrate the presence of interstitial clusters $200 \AA$ in diameter; these indicate that defects are mobile below room temperature.

Phosphorus ions, when ionimplanted into silicon in a random direction. penetrate further than expected. Explanations which have been suggested are diffusion and the scattering of ions into channelling directions. P. Blood and colleagues (Mullard Research Laboratories, Redhill and AERE Harwell), in a very elegant experiment, prepared a thin silicon crystal and implanted radioactive phosphorus ions into it. Diffusing ions would necessarily remain in the crystal, 